\title{
Giant Cell Tumor (GCT) of the Third Metatarsal in an Elderly Patient: A Rare Case Report
}

\author{
Neetin P Mahajan ${ }^{1}$, Amey Sadar ${ }^{1}$, Prasanna Kumar G S ${ }^{1}$, Ankit Marfatia ${ }^{1}$, Sunny M Sangma ${ }^{1}$, \\ Pranay Kondewar ${ }^{1}$
}

Learning Point of the Article:

Excision with ray amputation of the involved metatarsal helps in complete removal of the lesion and helps in early weight-bearing.

\section{Abstract}

Introduction: Giant cell tumour (GCT) is a benign osteolytic, locally aggressive lesion. Seen in young adults at the epiphysis. The most common site is long bones ( $85-90 \%)$. GCT of the metatarsal in elderly patients is very rare.

Case Report: A 60-year-old male came with complaints of pain and swelling over right foot dorsal aspect since for the last past one 1 year. There was no history of trauma. X-ray foot showed an osteolytic lesion in the right third metatarsal with thinning of the cortex. MRI and fine-needle aspiration cytology confirmed the diagnosis of GCT. The patient was managed by excision with the 3rd ray amputation. At present, 1.5 years follow-up, the patient is having no pain, difficulty in walking and no evidence of clinical and radiological recurrence.

Conclusion: Giant cell tumours could also present at uncommon sites, and they should be considered in the differential diagnosis oflytic lesions of the metatarsals. Excision with ray amputation of the involved metatarsal helps in complete removal of the lesion and helps in early weightbearing. This is the viable alternative treatment option in managing the metatarsal GCT in elderly patients.

Keywords: Giant cell tumour, third metatarsal, ray amputation.

\section{Introduction}

Sir Astley Cooper first described the giant cell tumor (GCT) in 1818. GCT of the bone is a benign lesion with local aggressiveness and tends to recur locally. The most common age of presentation is $20-40$ years in the epiphysio metaphyseal region. Commonly seen in long bones, of which $50 \%$ are seen in proximal tibia and distal femur region. Distal radius, proximal humerus and fibula are the other common locations. GCT of the foot and hand is rare, comprising about $1.5 \%$ and $2 \%$ respectively [1]. These hand and foot GCTs represent different lesions compared to long bone lesions [2]. In patients with foot GCT, the diagnosis is usually delayed/late as these are presents with vague symptomatology. The $\mathrm{X}$ ray of the bone shows eccentric lytic lesion with no periosteal reaction and the radiographic features of foot and hand GCTs are non-specific [3]. Magnetic resonance imaging (MRI) helps finding the exact location, extent of involvement, and also for differentiating GCT from other lesions. Histopathological examination is very essential for the confirmation of the diagnosis. The various treatment modalities available for the management of GCT are curettage and bone grafting, irradiation, amputation, and resection with reconstruction. Aggressive curettage or en block resection is the management of choice as the GCT has high local recurrence rate.

\section{Case Report}

A 60-year-old male presented with complaints of pain and swelling over the dorsum aspect of the right foot for the past 1

Author's Photo Gallery

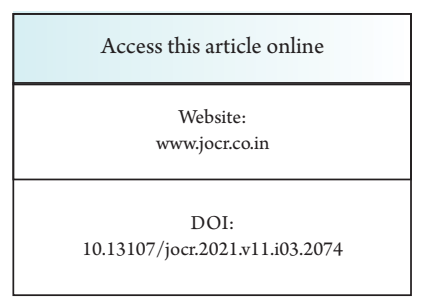

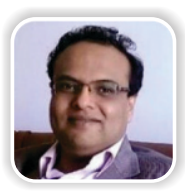

Dr. Neetin P Mahajan

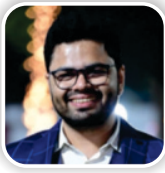

Dr. Amey Sadar

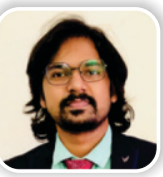

Dr. Prasanna Kumar G S

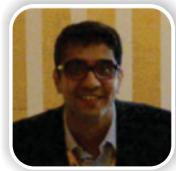

Dr. Ankit Marfatia

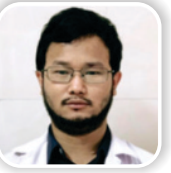

Dr. Sunny M Sangma

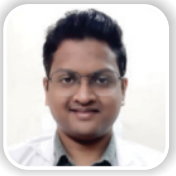

Dr. Pranay Kondewar
'Department of Orthopaedics, Grant Government Medical College and sir JJ group of hospitals, Mumbai, Maharashtra, India.

Address of Correspondence:

Dr. Prasanna Kumar G S,

Department of Orthopaedics, Grant Government Medical College and sir JJ group of hospitals, Mumbai, Maharashtra, India.

E-mail: prasannakumargs5@gmail.com

Journal of Orthopaedic Case Reports | pISSN 2250-0685 | eISSN 2321-3817 | Available on www.jocr.co.in | doi:10.13107/jocr.2021.v11.i03.2074 This is an Open Access article distributed under the terms of the Creative Commons Attribution Non-Commercial License (http://creativecommons.org/licenses/by-nc/3.0) which permits unrestricted non-commercial use, distribution, and reproduction in any medium, provided the original work is properly cited. 


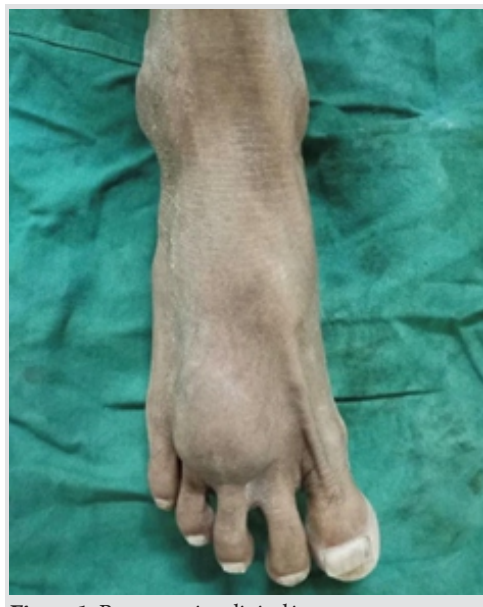

Figure 1: Pre-operative clinical image.

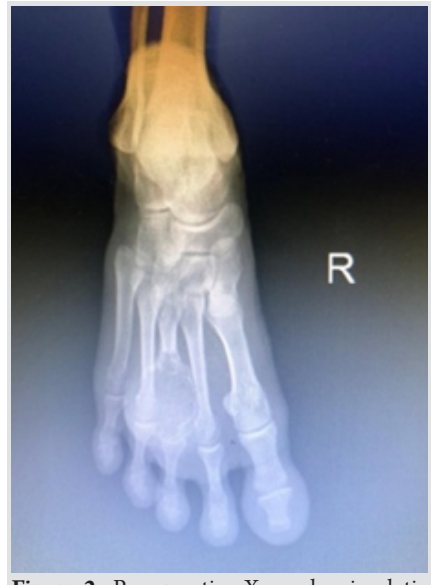

Figure 2: Pre-operative X-ray showing lytic lesion in the 3 rd metatarsal.

year. The patient was apparently alright 1 year back. There was no history of trauma, fever, loss of weight and loss of appetite. There was no history of previous surgeries. On examination, oval swelling measuring $5 \times 3 \mathrm{~cm}$ on the dorsum of the right foot was noticed opposing $2 \mathrm{nd}$, 3rd, and 4th metatarsal with welldefined margins (Fig. 1). The skin was free from the swelling and the consistency was firm. Tenderness was present with no signs of inflammation.

Radiographs of the right foot revealed an expansile osteolytic lesion in the 3rd metatarsal with cortical thinning sparing the proximal one-third of the bone. The tarsometatarsal joint appeared normal (Fig. 2). MRI foot showed well-defined expansile, solid cystic lesion of approximate size $4.4^{*} 3.1^{*} 3.1 \mathrm{~cm}$ arising from the medullary cavity of the distal shaft and head of the 3 rd metatarsal with surrounding soft-tissue edema with no soft-tissue extravasation and intra-articular extension. Fineneedle aspiration cytology was suggestive of GCT. As the patient was an elderly manual laborer and wanted early weightbearing, we planned for excision with 3rd ray amputation.

The patient was operated under spinal anesthesia, in the supine position. The incision was taken over the dorsum of the foot over 3rd metatarsal. Soft tissue was dissected and extensor

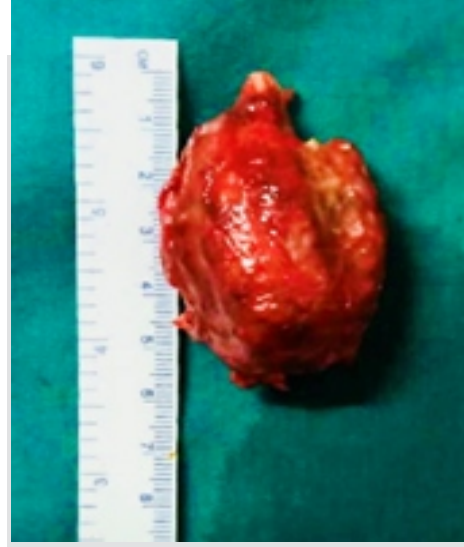

Figure 5: The excised tumor mass measuring around $6 \mathrm{~cm}$ in length.

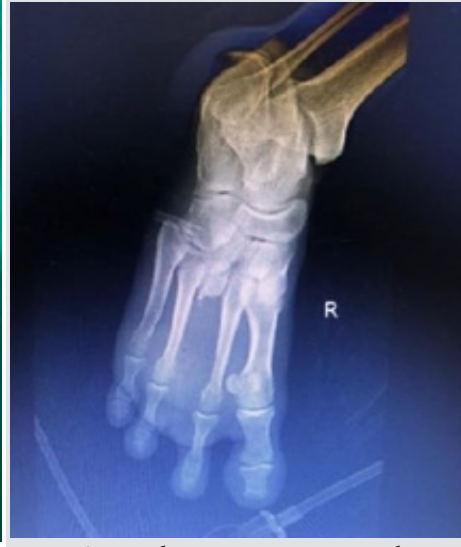

Figure 6: Immediate post-operative X-ray showing complete removal of tumor mass with the 3 rd ray amputation.

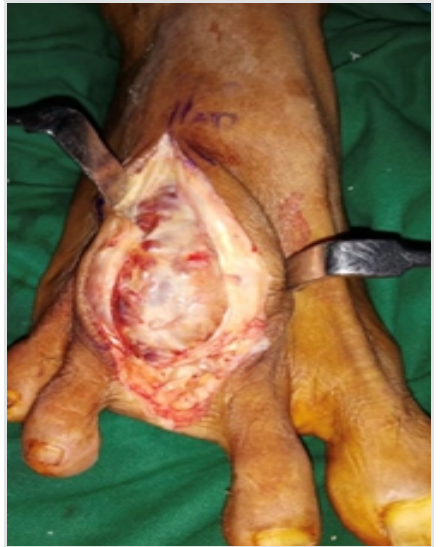

Figure 3: Intraoperative picture showing the tumor mass after superficial dissection and third toe removal.
tendons were separated, GCT mass was identified and was removed along with the $3 \mathrm{rd}$ metatarsal sparing proximal $1 \mathrm{~cm}$ without disturbing tarsometatarsal joint (Fig. 3, 4). Excised Specimen was measuring approximately about $6^{*} 3 \mathrm{~cm}$ which was sent for histopathology examination (Fig. 5). Hemostasis was achieved and the wound was closed in layers.

Immediate post-operative X-ray foot showed complete removal of the tumor mass with the 3rd ray amputation (Fig. 6). Histopathological examination confirmed the diagnosis of GCT (Fig. 7). Post-operative period was uneventful, weightbearing was started after 3 weeks of surgery. At present, 1.5 years follow-up, the patient is comfortable with no pain and difficulty in walking (Fig. 8). Follow-up X-ray showed no recurrence with no other lesions (Fig.9).

\section{Discussion}

GCT of the bone is a benign, locally aggressive bone lesion. It is consisted of stromal cells and multinucleated giant cells [4, 5]. GCTs of the metatarsal bones are more aggressive than the other bones. The main presentation of the metatarsal GCT is pain similar to the conventional GCT found in other locations. The swelling is hard, non-mobile and on X-ray, it appears as
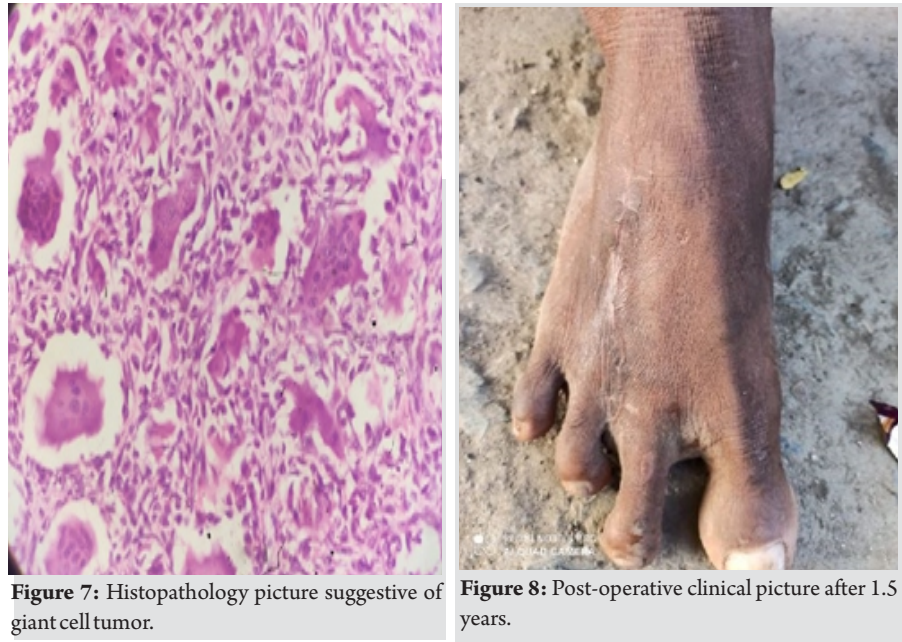


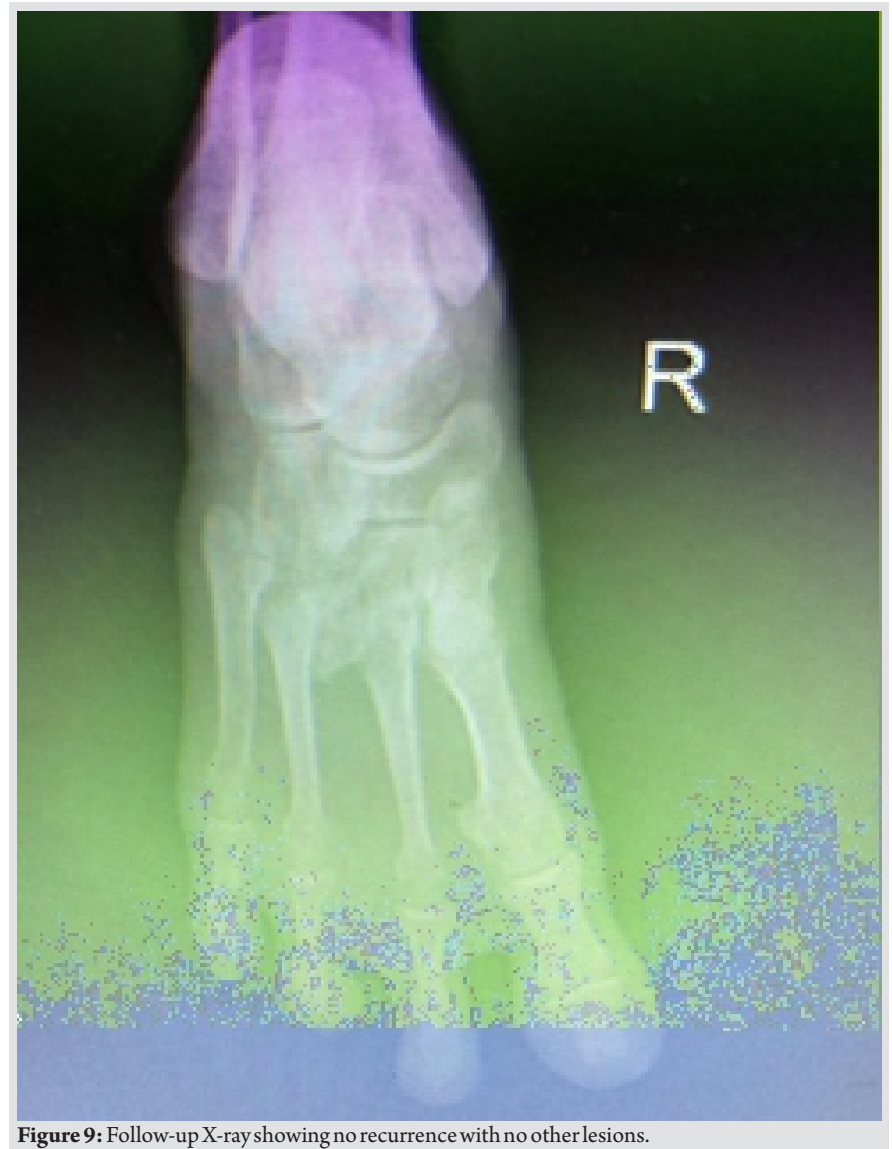

expansile lytic lesion with the thinning of cortex. Our patient had all these characteristic features. It usually occurs in young adults of 20-40 years in the epiphysio metaphyseal region.

GCT mainly occurs in the long bones (75-90\%) mainly in the lower end of the femur and upper end of the tibia. Other common sites include distal radius and humerus. GCTs of the hand and foot bones are rare and foot is even rarer than of hand lesion. The lytic lesions of the foot often have mixed clinical features and thus making the diagnosis difficult. The differential diagnoses should be kept in mind while diagnosing the GCT. Giant cell reparative granuloma, chondromyxoid fibroma, the brown tumor of hyperparathyroidism, aneurysmal bone cyst, angiosarcoma, myeloma, and an expansile metastatic lesion, such as renal cell carcinoma, can mimic GCT. Curettage and bone grafting, irradiation, amputation, and resection with reconstruction are the various management options available

\section{References}

1. Unni KK. Dahlin's Bone Tumors: General Aspects and Data on 11,087 Cases. 5th ed. Philadelphia, PA: LippincottRaven; 1996.p. 263-83.

2. Mohan V, Gupta SK, Sharma OP, Varma DN. Giant cell tumor of short tubular bones of the hands and feet. Indian J Radiol 1980;34:1-17. for the management $[2,6,7,8]$. Clinical presentations such as age , duration of symptoms and radiological findings such as site, extent of the tumor into surrounding soft tissue, and absence of periosteal reaction help in differentiating GCT from other lesions. No history of fever, weight loss, anorexia, and no response to antitubercular treatment help to exclude tuberculosis. An aneurysmal bone cyst is commonly seen in the second decade and presents as a firm, slowly enlarging mass. Giant cell reparative granuloma is uncommon, it is benign with intra osseous reactive lesion, usually located in metatarsal, the radiological and histological features may mimic GCT. The clinical nature of the GCT of the metatarsal bone is determined by the limited space on the dorsum of the foot, and the common finding is the soft-tissue swelling.

Prashant et al. reported metatarsal GCT case which was managed with excision and reconstruction using fibula autograft with good outcome [9]. The above-mentioned technique is difficult to perform in elderly patients because of underlying comorbidities, it may cause delayed union, nonunion, fracture at the graft site, which may require secondary procedures latter and also the weight-bearing is delayed. As our patient was an elderly manual laborer and wanted early weightbearing, we have done excision with 3rd ray amputation, which has given good results. The disadvantage of this procedure is cosmetic, which should not be a significant concern in managing elderly patients with GCT.

\section{Conclusion}

GCTs could also present at uncommon sites, and they should be considered in the differential diagnosis of lytic lesions of the metatarsals. Excision with ray amputation of the involved metatarsal helps in removal of the lesion completely and helps in early weight-bearing. This is the viable alternative treatment option in managing the metatarsal GCT in elderly patients.

\section{Clinical Message}

Early diagnosis and proper management of metatarsal GCT are essential to get a better outcome with no local recurrence. Late diagnosis can lead to pathological fracture and related morbidity.
3. Mendicino SS. Giant cell tumor of the first metatarsal bone en bloc resection with autogenous middle fibular strut graft. J Foot Ankle Surg 1993;32:405-10.

4. Bertoni F, Bacchini P, Staals EL. Malignancy in giant cell tumor of bone. Cancer 2003;97:2520-9.

5. Huvos AG. Bone Tumors: Diagnosis, Treatment and 
Prognosis. Philadelphia, PA: Saunders; 1991.p.429-67.

6. Cavender RK, Sale WG 3rd. Giant cell tumor of the small bones of the hands and feet: Metatarsal giant cell tumor. W VMed J 1992;88:342-5.

7. Wold LE, Swee RG. Giant cell tumor of the small bones of the hands and feet. Semin Diagn Pathol 1984;1:173-84.
8. Burns TP, Weiss M, Snyder M, Hopson CN. Giant cell tumor of the metatarsal. Foot Ankle 1988;8:223-6.

9. Prashant K, Bhattacharyya TD, Frank H, Ram P. An unusual case of giant cell tumor of first metatarsal: A rare case report and review of literature. J Orthop Case Rep 2016;6:3-6.

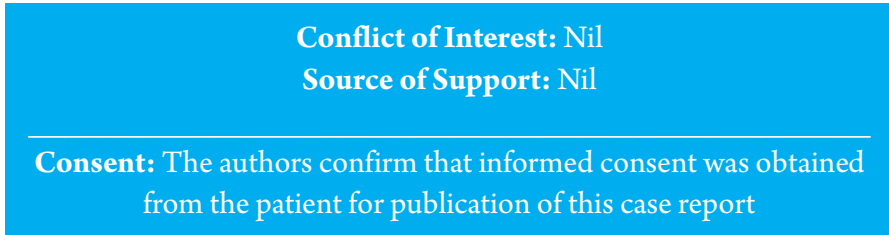

Conflict of Interest: Nil

of Support: Nil

from the patient for publication of this case report

\section{How to Cite this Article}

Mahajan NP, Sadar A, Kumar G S P, Marfatia A, Sangma SM, Kondewar P. Giant Cell Tumor (GCT) of the Third Metatarsal in an Elderly Patient: A Rare Case Report. Journal of Orthopaedic Case Reports 2021 March;11(3):29-32. 